\title{
EDUCAÇÃO AMBIENTAL POR MEIO DA CONTAÇÃO DE HISTÓRIA "A BORBOLETA AZUL"1
}

\author{
ENVIRONMENTAL EDUCATION BY STORYTELLING OF \\ "THE BLUE BUTTERFLY”
}

\author{
Janine Farias Menegaes ${ }^{2}$ e Fernanda Alice Antonello Londero Backes ${ }^{3}$
}

\section{RESUMO}

A Educação Ambiental dentre outros temas, tem como finalidade desenvolver o homem como um ser interdisciplinar. Assim, objetivou-se através da contação de história "A borboleta azul", estimular e despertar para conceitos da Educação Ambiental em alunos da educação infantil em uma escola de Santa Maria, RS. A contação da história supracitada ocorreu de maneira lúdica utilizando imagens projetadas em forma eletrônica-visual. Ao longo da contação, observou-se o interesse dos alunos, em que todos demonstraram vontade em participar dos acontecimentos vividos pela borboleta azul e, ao final da história, demonstraram tristeza com o final infeliz, que precisou ser modificado. Verificou-se que todos os alunos tem conhecimentos relacionados a Educação Ambiental, como a preservação dos animais, plantas e água e que a natureza, em sua concepção é limpa, bela e bem cuidada.

Palavras-chave: conto infantil; percepção ambiental; sustentabilidade.

\begin{abstract}
Environmental Education, among other themes, aims to develop the man as an interdisciplinary being. Thus, the objective was, through the storytelling of "The Blue Butterfly", to stimulate and evoke concepts of Environmental Education in early childhood students in a school in Santa Maria, RS. The telling of the aforementioned story occurred in a playful manner, using images projected in electronic-visual form. Throughout the story, the students' interests were observed, in which all showed willingness to participate in the events experienced by the blue butterfly and, at the end of the story, showed sadness with the unfortunate ending, which needed to be modified. It was found that all students have knowledge related to environmental education, such as the preservation of animals, plants and water and that nature, in its conception is clean, beautiful and well cared for.
\end{abstract}

Keywords: children's tale; environmental perception; sustainability.

\footnotetext{
${ }^{1}$ Relato de experiência

${ }^{2}$ Engenheira Agrônoma, Doutora, Acadêmica do Curso de Pós-Graduação em Educação Ambiental - UFSM. E-mail: janine_rs@hotmail.com

${ }^{3}$ Pedagoga e Engenheira Agrônoma, Doutora, Professora do Departamento de Fitotecnia - UFSM. E-mail: profe.fernanda. backes@gmail.com
} 


\section{INTRODUÇÃO}

A Educação Ambiental é um componente essencial e permanente da educação nacional, devendo estar presente, de forma articulada, em todos os níveis e modalidades do processo educativo, em caráter formal, informal e não formal (BRASIL, 1999). Neste sentido, a Educação Ambiental, de acordo com a Lei nº 9.795 (1999), no artigo primeiro têm-se:

Art $1^{\circ}$. Entende-se por Educação Ambiental os processos pelo meio dos quais o indivíduo e a coletividade constroem valores sociais, conhecimentos, habilidades, atitudes e competências voltadas para a conservação do Meio Ambiente, bem do uso comum do povo, essencial à sadia qualidade de vida e sua sustentabilidade.

A Educação Ambiental adquire função transformadora atuando diretamente na condição do sujeito como indivíduo integrante e corresponsável por promover um desenvolvimento sustentável, frente a degradação socioambiental (JACOBI, 2005). Educar para a cidadania é uma prática política que permite dispor de argumentos que ajudem a continuar reivindicando uma educação diferente em busca de um futuro melhor, tomando consciência de que os novos conceitos referentes à educação devem estar acompanhados de reformas nos sistemas sociais, para que ocorram as mudanças necessárias (HAMMES; RACHWAL, 2012).

O uso de histórias infantis para despertar a imaginação e a criatividade, além de imprimir conceitos nas crianças é uma atividade essencial e deve ser utilizada pelos professores na educação infantil. O principal significado de escutar histórias é uma possibilidade de descobrir o mundo imenso dos conflitos, das dificuldades, das soluções, que o indivíduo vive, de um jeito ou de outro, por meio dos problemas que serão enfrentados e resolvidos pelos personagens da história contada (DIAS, 2003; ABRAMOVICH, 2013; TUAN, 2012).

É através da leitura da história que as percepções, os sentimentos, as emoções e os conceitos serão sentidos e formulados pelo leitor. Segundo Góes (1990), a literatura infantil pode influenciar na formação da criança, que passa a conhecer o mundo em que vive de maneira a compreender a dualidade, por exemplo, o bem e o mal, o certo e o errado, o belo e o feito, o amor e a raiva, a dor e o alívio, o positivo e o negativo, entre outros.

O livro é elemento fundamental no extraordinário universo da criança - esta é, pelo menos, a mensagem explicitada na imagem que complementa o texto no livro infantil. Nesta perspectiva está evidenciada na regularidade com que se verifica a representação de livros, como imagem, característica dos livros infantis. Essa regularidade deveria, portanto, ser considerada nos processos de seleção para o desenvolvimento de coleções destinadas à criança (SANTO, 2008).

Assim, o objetivo deste trabalho foi, através da contação de história “A borboleta azul”, estimular e despertar para conceitos da Educação Ambiental em alunos da educação infantil em uma escola de Santa Maria, RS. 
A Educação Ambiental pretende desenvolver o homem de forma interdisciplinar para que o mesmo possa adquirir valores e atitudes necessários para lidar com as complexidades das situações-problemas e encontrar soluções sustentáveis. Além de, passar a se incluir no processo de percepção a qual faz parte do meio ambiente, atuando como sujeito que age, interfere e integra este meio (DIAS, 2003; MENEGAES et al., 2016).

Educar para a cidadania é uma prática filosófica e política que permitem dispor de argumentos que ajudem a continuar reivindicando uma educação diferente e global, em busca de um futuro melhor. Em que o envolvimento nas esferas sociais, econômicas e culturais são indispensáveis para chegar a uma proposta de ação pedagógica comprometida com o homem e seu tempo (RAYS, 1996; HAMMES; RACHWAL, 2012).

A educação é uma prática social, materializada numa atuação efetiva na formação e desenvolvimento de seres humanos, em condições socioculturais e institucionais concretas, implicando práticas e procedimentos peculiares, visando mudanças qualitativas na aprendizagem (LIBÂNEO, 2008).

A educação por sua vez se funda como um processo permanente, sendo que as pessoas se tornam educáveis na medida em que se reconhecem inacabados (FREIRE, 2003). Onde valores sociais trazem consigo a conscientização de que se vive em sociedade e que a natureza é de todos, e que cada um influência de alguma maneira o espaço em que vive, com pequenas mudanças de hábitos, muito pode ser feito pelo todo. O indivíduo no momento que começa a pensar no seu bem estar ao mesmo tempo já começa a colaborar para um mundo melhor, pois vai deixar de ter algumas atitudes que, às vezes podem contribuir e muito, para a melhoria socioambiental do seu meio (BRANCO, 2003; LOUREIRO, 2012).

A escola desempenha um importante papel no sentido no sentido de difundir crenças, ideias, valores, entre outros, compatíveis com o período social e cronológico (passado e presente). A relação entre homem-ambiente-sociedade envolve vários fatores intrínsecos ao ser humano, resultado das interações emocionais, do meio social (familiar e cultural) em que ele está inserido, sendo carregados de signos e suas representações. Onde sua transformação ocorre por meio da percepção, sobretudo, a ambiental (PROCHNOW; SILVEIRA, 2017).

A percepção é tanto a resposta dos sentidos aos estímulos externos como atividade proposital, na qual certos fenômenos são claramente registrados, enquanto outros retrocedem para a sombra ou são bloqueados. Muito do que percebemos tem valor para nós, para a sobrevivência biológica, e para propiciar algumas satisfações que estão enraizadas na cultura (TUAN, 2012).

Práticas didático-pedagógicas, como a contação de história favorecer o diálogo na sala de aula, a fim de possibilitar a reflexão dos sujeitos, sobre o meio em que interagem - percebendo-o (BRITO; 
OLIVEIRA, 2014). Para Segawa (1996) a consciência humana diante de um ambiente torna-se um produto do potencial imaginativo e criativo, em que a contemplação visual é formulada através de significados e novas imagens.

Histórias contadas através de desenhos deixaram vestígios desde a Pré-História, nas pinturas rupestres que documentam rituais de caça, consideradas precursoras das histórias em quadrinhos; e na Antiguidade, as pinturas das paredes de grandes pirâmides do Egito ou nas imagens mitológicas esculpidas nas cerâmicas gregas (ALVES, 2001; SANTO, 2008). Para Busatto (2003), a importância de se contar histórias é para formar leitores, valorizar as etnias existentes, manter viva a História, encantar e sensibilizar o ouvinte e, além disso, é estimular o imaginário, articular o sensível, tocar o coração do ouvinte, alimentar o espírito, resgatar significados para a nossa existência e reativar o sagrado.

A contação de histórias é uma prática essencial para o desenvolvimento e aprendizagem da criança, que desde pequena sente a necessidade de vivenciar seus sonhos, suas fantasias e seus encantos por meio da arte. É na infância que se constroem as primeiras experiências de vida que subsidiarão a formação do caráter, da personalidade e da consciência (FARIA et al., 2017).

Neste contexto, a sensibilização humana se dá por meio de signos, figuras, fotografias e paisagens, que servem de base referencial a um novo pensamento, desde a forma de pensar e agir diferente do habitual, tendo como instrumento perceptivo para a Educação Ambiental, a partir das concepções históricas adquiridas ao longo do seu crecimento como cidadão. Possibilitando de maneira individual sua tomada de consciência, que é algo intrínseco e altruísta do ser humano sobre o ambiente em que vive e como as questões socioambientais do seu cotidiano pode afetar a sua existência (SILVA, 2001; BORGES et al., 2010).

Assim, a problemática socioambiental é um assunto recorrente e atual que deve permear as discussões diárias e constantes, especialmente, no ambiente escolar, base da comunicação, informação e popularização de diversos temas e práticas ambientais essenciais a formação do cidadão para o mundo. Entre os sentidos de compreensão do ser humano a visão, tem como função transmitir suas ideias através de signos, símbolos e imagens, passa a ser ainda mais relevante e significativas as discussões acerca das temáticas abordadas (BORGES et al., 2010; PETRY, 2014).

Os olhos obtêm informações muito precisas e detalhadas, sobre o meio ambiente, do que os ouvidos, mas geralmente somos mais sensibilizados pelo que ouvimos do que pelo vemos (TUAN, 2012).

Deste modo, a importância da contação de histórias explora vários os sentidos durante sua execução, a visão permitindo conhecer o mundo externo, desde a formação a interpretação e reconhecimento das imagens, e a audição com conotação de passividade (receptividade) ao que somos e aos estímulos que recebemos desde bebê (TUAN, 2012). 


\section{MATERIAL E MÉTODOS}

A metodologia aplicada ocorreu com a visita do grupo Jardim na Escola da Universidade Federal de Santa Maria (UFSM) a Escola Municipal de Educação Infantil João Franciscatto, localizada no bairro São José, no município de Santa Maria, RS.

O grupo Jardim na Escola é composto por acadêmicos e professores da UFSM de diversas áreas do conhecimento que busca junto às escolas do município desenvolver usos e técnicas de paisagismo visando melhorar o ambiente que as cercam. Tendo como objetivo principal a Educação Ambiental, a qual é desenvolvida com os alunos de educação infantil por meio de contos lúdicos e atividades pedagógicas.

A Escola Municipal de Educação Infantil João Franciscatto, em funcionamento há 21 anos, atualmente disponibiliza turmas de Maternal 1 e 2 (crianças com faixa etária de 2 a 4 anos), Pré-A (crianças com faixa etária de 4 a 5 anos) e Pré-B (crianças com faixa etária de 5 a 6 anos), nos turnos da manhã, composta de 70 alunos e, tarde, composta de 79 alunos, totalizando 149 alunos. Os professores e colaboradores da escola tem se dedicado a atividades de Educação Ambiental e desenvolvem atividades com os alunos, principalmente, referentes aos cuidados com as plantas, animais e a reciclagem de lixo. Expandido estas atividades junto aos pais e a comunidade.

Os integrantes do grupo Jardim na Escola em visita a escola desenvolveram a atividade contação de história com a leitura do livro "A borboleta azul” (Figura 1A) da autora Lenira Almeida Heck (2008), de maneira lúdica utilizando imagens projetadas em forma eletrônica-visual, com a interpretação da história, bem como, a explicação do ciclo de vida dos insetos, da classe animal Insecta e ordem Lepidoptera a qual a borboleta faz parte (Figura 1B).

Figura 1 - A: Capa do livro “A borboleta azul”. B: Ciclo de metamorfose da borboleta (Ordem Lepidoptera).

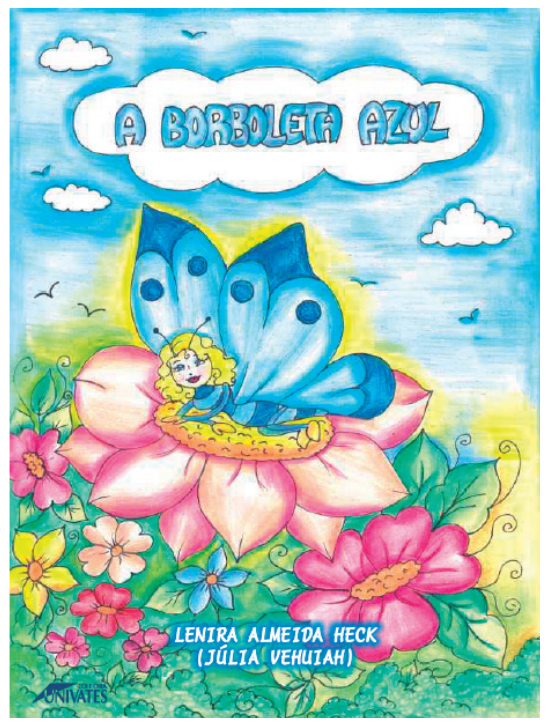

A

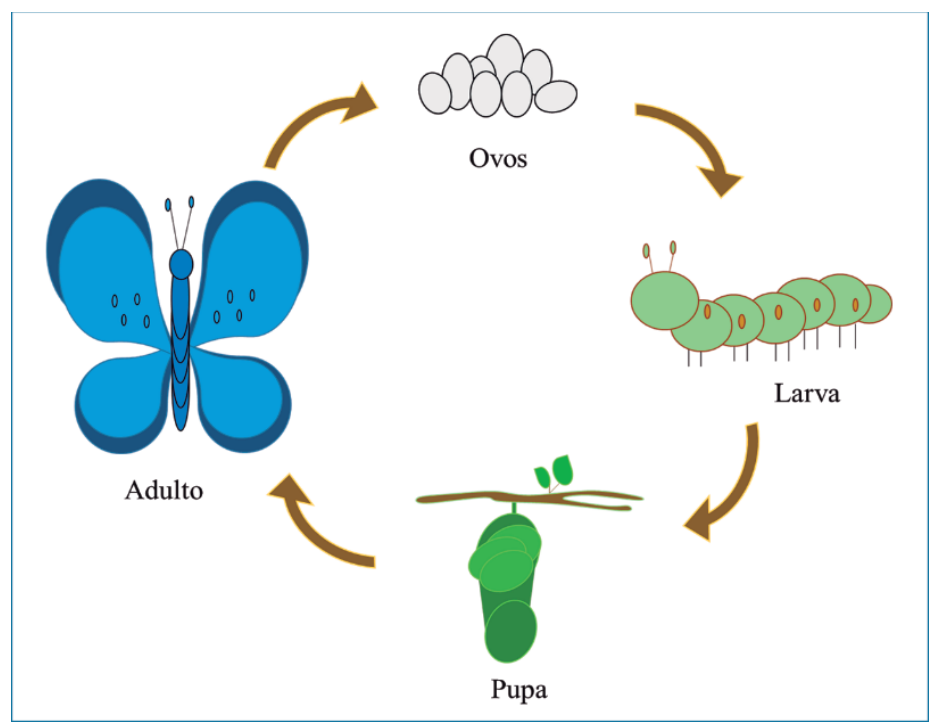

$\mathrm{B}$

Fonte: A: Heck (2008). B: Autores (2013). 
A ordem Lepidoptera inclui as borboletas e mariposas, com aproximadamnete 180 mil espécies, no Brasil se tem em torno de 5 mil espécies. O nome desta ordem refere-se à presença de escamas nas asas, do grego lepis = escamas, e pteron = asas. São insetos com ciclo de metamorfose completa denominado holometábolo: ovo, larva (largarta), pupa (crisálida) e adulto (Figura 1B), de asas membranosas, corpo e apêndices cobertos por escamas. A postura dos ovos, geralmente, são em folhas próximo a fonte de alimento, no estágio larval é a fase de alimentação do inseto durante todo o ciclo de vida, armazenando energia para as próximas fases da vida. Durante o estágio de pupa, o inseto passa por grandes metamorfoses até chegar ao estágio de adulto, no empupamento o inseto se isola formando um casulo. A transformação final é a fase adulta quando o inseto voa, é também o estágio em que se realiza cópula e postura dos ovos (CAMARGO et al., 2015).

A partir da história foi solicitado às crianças (faixa etária de 2 a 6 anos) que elaborassem um desenho sobre o entendimento do conto infantil. Além disso, foi proporcionado as mesmas uma elaboração de pensamentos e falas por meio do tema Educação Ambiental, respeito e cuidados ao meio ambiente, temas esses norteadores da história infantil. Posteriormente, os desenhos foram interpretados pelos alunos que também explicitaram, com satisfação, a visita do grupo Jardim na Escola.

\section{RESULTADOS E DISCUSSÃO}

Durante a contação da história infantil "A borboleta azul” verificou-se um forte interesse por parte dos alunos, independentemente da faixa etária (Figura 2). Todos os alunos participaram ativa e constantemente, ao longo da história, os mesmos foram interferindo e ajudando na hora do conto. O hábito da contação de história para Souza e Bernardino (2011), favorece a narração e processos de alfabetização e letramento, com ótimos resultados no desenvolvimento cognitivo referente ao saber explicar, descrever, atribuir nomes, entre outros.

Figura 2 - A: Contação da história. B: Interesse demonstrado pelos alunos e professores em ouvir e participar da história durante a hora do conto.

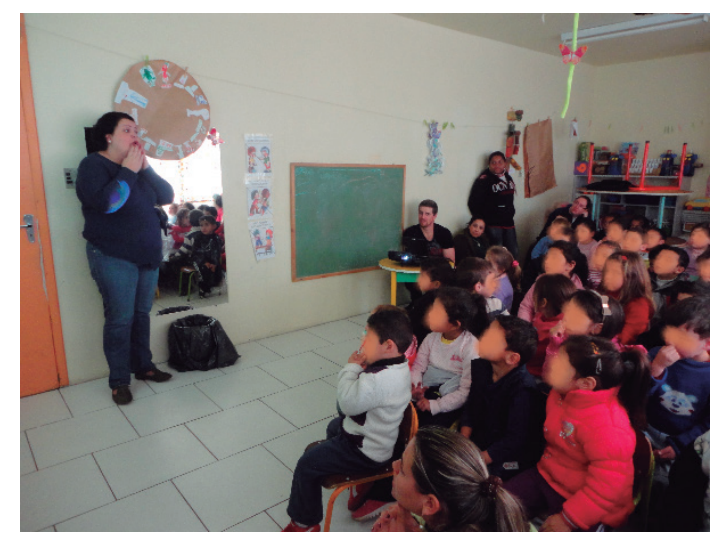

A

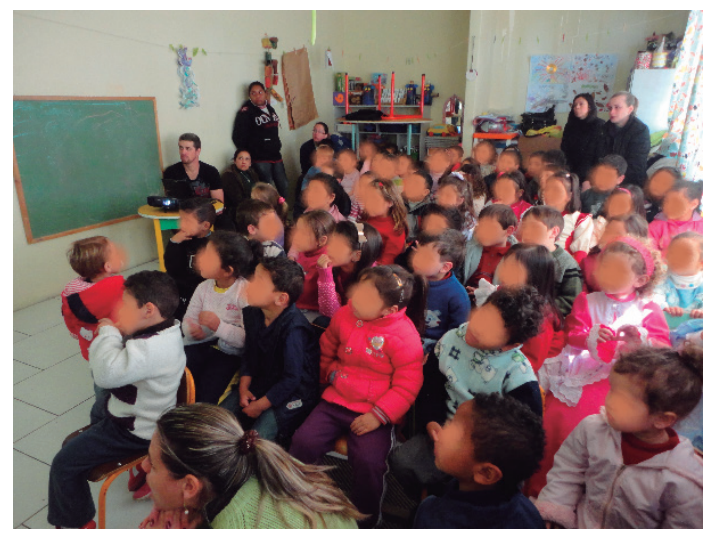

$\mathrm{B}$

Fonte: Autores. 
Os alunos verbalizaram que ainda não conheciam a história contada e durante os acontecimentos que se passaram durante a história verificou-se o conhecimento sobre a natureza dos mesmos sobre aos relativos a Educação Ambiental, conceitos sobre a preservação do ambiente e a existência de animais e suas vivências. Os alunos, de forma geral, destacaram a necessidade de preservar os animais, as plantas e a água. Alguns manifestaram o interesse em contar sobre o seu animal de estimação e os cuidados que tem com ele.

De acordo com Brito e Oliveira (2014), há diferentes formas de percepção do mundo, sobre a prática e o entendimento da Educação Ambiental, em que é fundamentado pelo diálogo. Na vertente Freireana o diálogo possibilita a reflexão sobre as perspectivas do sujeito a respeito do mundo em que está inserindo e agindo em sociedade. Para Peres et al. (2018), a importância da participação dos alunos nas práticas pedagógicas, pois estas práticas, por exemplo, a contação de história. Caracteriza-se por um despertar aos sonhos e encantos ao mundo literário, facilitando sua forma de aprendizagem.

Ao longo da contação da história, quando se mencionava as fases de vida da borboleta um aluno (6 anos) manifestou-se seu conhecimento sobre os estágios do inseto, dizendo: "que a largarta antes de se transformar em borboleta para voar, forma uma casinha que se chama crisálida”. Depois da intervação por parte do aluno, verificamos que seus pais são biólogos e incentivam o filho no conhecimento de insetos e demais animais.

Para Araújo et al. (2017), a atividade de contação de histórias possibilita trocas linguísticas desde vocabulário a reflexões sobre o que a história "quer dizer", perpassando por pensamentos e sentimentos dos personagens, a qual deve ser estimulada pelos pais e aprimorada na escola.

A participação dos alunos foi acentuada, principalmente, quando no final da história o não tinha final feliz. Alguns pediram que mudássemos o final e então foi solicitado pelo grupo Jardim na Escola um novo final e que este fosse criado pelos alunos. Todos queriam que a borboleta não ficasse presa para sempre na exposição e que um final feliz fosse novamente inventado. O que prontamente foi atendido por todos que usaram muita criatividade. Para eles, a borboleta azul deveria sair voando livre e viveria feliz para sempre na natureza em companhia de outros animais e de muitas flores. A natureza, na concepção dos pequenos, é bela, cuidada, limpa e conservada.

De acordo com Faria et al. (2017), quando a criança é confrontada com bons sentimentos na contação da história se identificam, por trazerem em si a semente da bondade e autenticidade. Contudo, quando o oposto ocorre, como na história contada, em seus impasses sentimentais buscam solucionar esses problemas. E, para Góes (1990), o dualismo (bem/mal, certo/errado) é inerente a educação infantil, em que sua compreensão deste dualismo depende do contexto ambiental que está inserido por suas percepções.

Em um segundo momento foi solicitado às crianças que elaborassem um desenho (Figura 3) sobre o seu entendimento da história, a utilização desta técnica pedagógica é devido às mesmas ainda não estão alfabetizadas. A história contada causou diversos sentimentos às crianças, pois elas queriam que a borboleta azul chamada no conto de Fifi, tivesse um final feliz e que a mesma fosse livre. 
Segundo Silva (2010), o desenho é uma forma de representação dos sentimentos e pensamentos humanos, que permite a comunicação e a expressão do que está sendo vivênciado. Para Guedes e Vialou (2016), a importância do desenho como aparato cognitivo, pois na evolução humana, mesmo que inconscientemente, o homem tente a registra seu aprendizado, a prova disso vai da arte rupestre a fotografia digital.

Tavares (2009) cita que o desenho é a representação do mundo natural, fundamentado na teoria e de valor individual do autor, expressando seus sentimentos visíveis e não visíveis. Assim, verificou-se que os alunos puderam livremente expor seus sentimentos em relação a história contada mesclando com seus conhecimentos sobre a natureza, neste caso preservação e conservação.

Os desenhos foram criativos e detalhistas, o que demonstra a atenção deles na história, conforme a Figura 3, tais como: nas imagens B, F, I e J - o destaque para o voo livre da borboleta Fifi; na imagem $\mathrm{C}, \mathrm{D}, \mathrm{N}$ e P - evidenciam a metamorfose do inseto na árvore; nas imagens $\mathrm{E}, \mathrm{H}$ e $\mathrm{K}$ - detalham a postura de ovos; nas imagens A, L e M - tem-se desenhos de flores e de borboletas; na imagem $\mathrm{G}$ - houve o desenho de pessoas, pois foi relatado que os humanos também fazem parte do meio ambiente e devem ser cuidados como os demais "moradores".

Para Faria et al. (2017), a importância da contação de história como recurso de transmissão de valores tanto para adultos quanto para crianças. Segundo Araújo et al. (2017), o desenvolvimento das habilidades sociocognitivas se dá pela interação das relações sociais, conforme ocorre o entendimento do comportamento e dos sentimentos pessoais. Os autores, também, concordam que a contação de história pode ser um entremeio da perservação histórica tradicional a novas formas de pensar conceitos, principalmente, relacionados a Educação Ambiental.

Figura 3 - Alguns desenhos dos alunos depois da hora do conto.

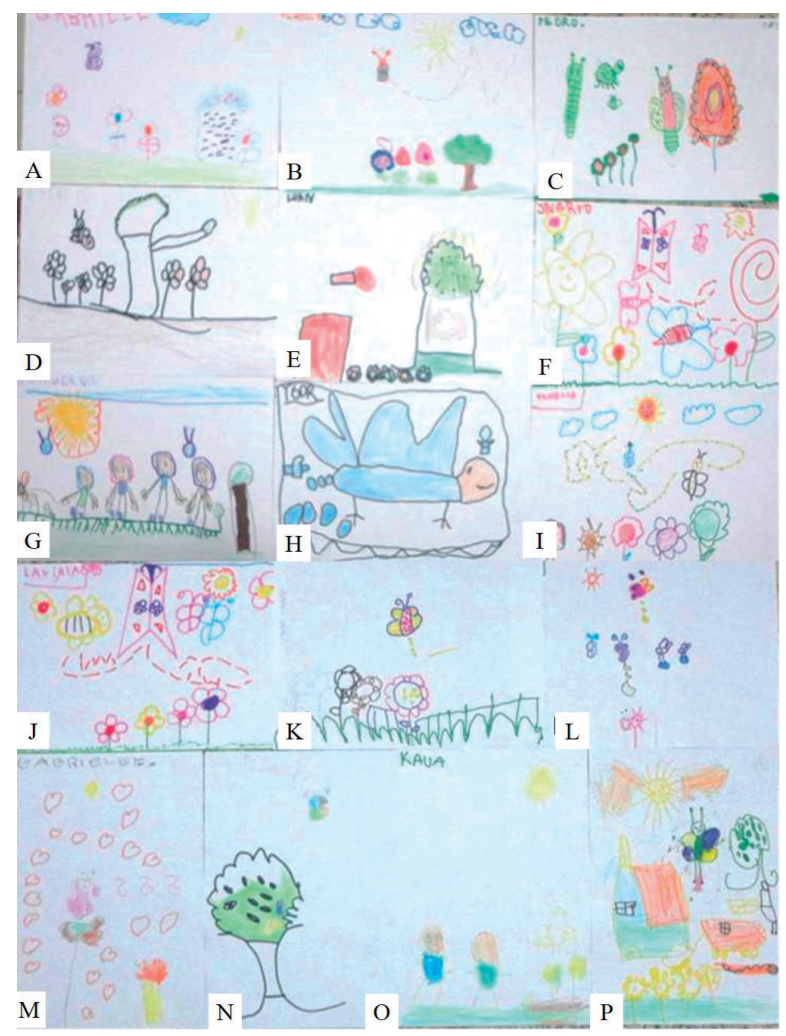

Fonte: Autores. 


\section{CONSIDERAÇÕES FINAIS}

Os alunos e professores do turno da manhã da Escola Municipal de Educação Infantil João Franciscatto demonstraram muito interesse com a visita do grupo Jardim na Escola.

Os alunos tratam o tema Educação Ambiental com muita seriedade, o que demonstra que os professores da escola estão preocupados e compromissados com a preservação do meio ambiente.

Os alunos ficaram muito felizes com a hora do conto e participaram ativamente durante toda a história, demonstrando sentimentos de afeto, alegria, tristeza e surpresa ao longo de toda a história.

Toda a comunidade escolar solicitou novas visitas para tratar de assuntos variados referentes à Educação Ambiental, o que demonstra interesse e compromisso por parte da escola.

\section{REFERÊNCIAS}

ABRAMOVICH, F. Por uma arte de contar histórias. Disponível em: http://www.docedeletra.com. br/semparar/hspfanny.html. Acessado em: 19 de setembro de 2019.

ALVES, J. M.. História em quadrinhos e educação infantil. Psicologia: ciência e profissão, Brasília, v. 3, n. 1, p. 2-8, 2001.

ARAUJO, G. B. et al. Termos mentais na contação de histórias e a teoria da mente das crianças. Psicologia: Teoria e Pesquisa, v. 32, n. 4, p. 1-9, 2017.

BORGES, M. D. et al. A fotografia de natureza como instrumento para educação ambiental. Ciência \& Educação, v. 16, n. 1, p. 149-161, 2010.

BRANCO, S. Educação Ambiental: metodologia e prática de ensino. Rio de Janeiro: Dunya, 2003. 80p.

BRASIL. MINISTÉRIO DO MEIO AMBIENTE. Lei n. 9.795 (27/04/1999) - Política Nacional de Educação Ambiental e dá outras providências. Acesso em: 20 abr. 2019. Disponível em: https:// bit.ly/344usA9

BRITO, R. A.; OLIVEIRA, G. F. A prática dialógica - argumentativa nas aulas de educação socioambiental. Ambiente \& Educação, v.19, n. 1, p. 207-2019, 2014.

BUSATTO, C. Contar e encantar - pequenos segredos da narrativa. Petrópolis: Vozes, 2003. 
CAMARGO, A. J. A. et al. Coleções Entomológicas: Legislação Brasileira, coleta, Curadoria e Taxonomia para as principais Ordens. Planaltina: Embrapa Cerrados, (E-Book). 2015. 117p.

DIAS, G. F. Educação ambiental: princípios e práticas. 8. ed. São Paulo: Gaia, 2003.

FARIA, I. G. et al. A influência da contação de histórias na Educação Infantil. Mediação, v. 12, n. 1, p. $30-48,2017$

FREIRE, P. Pedagogia da Autonomia: saberes necessários à prática educativa. São Paulo: Paz e Terra, 2003.

GÓES, L. P. A aventura da Literatura para crianças. São Paulo: Melhoramentos, 1990.

GUEDES, C.; VIALOU, D. Símbolos na arte rupestre sob o olhar da Arqueologia Cognitiva: considerações analíticas sobre o sítio Conjunto da Falha, Cidade de Pedra, Rondonópolis, Mato Grosso. Boletim do Museu Paraense Emílio Goeldi. Ciências Humanas, v. 12, n. 1, p. 101-123, 2017.

HAMMES, V. S.; RACHWAL, M. F. G. Educação ambiental - para o desenvolvimento sustentável. Meio ambiente e a escola. Brasília, Embrapa, v. 7. p. 43-53, 2012.

HECK, L. A. A borboleta azul. Ed. UNIVATES. Lajeado, 2008. 28p.

JACOBI, P. R. Educação ambiental: o desafio da construção de um pensamento crítico, complexo e reflexivo. Educação e Pesquisa, v. 31, n. 2, p. 233-250, 2005.

LIBÂNEO, J. C. O campo teórico-investigativo da pedagogia, a pós-graduação em educação e a pesquisa pedagógica. Revista Educativa (UCG), v. 11, n. 1, p. 1-15, 2008. DOI: 10.18224/educ.v11i1.662

LOUREIRO, C. F. B. Trajetórias e Fundamentos da Educação Ambiental. 4. ed. São Paulo: Cortez, 2012. 168p.

MENEGAES, J. F. et al. Práticas de paisagismo em espaços de convivência social em comunidades rurais e em centro de educação ambiental. Revista Monografias Ambientais - REMOA, Santa Maria, v. 15, n. 1, p. 381-392, 2016. DOI: 10.5902/2236130819947 
PERES, S. G. et al. Recursos simbólicos e imaginação no contexto da contação de histórias. Psicologia Escolar e Educacional, São Paulo, v. 22, n. 1, p. 151-161, 2018. DOI: 10.1590/2175-35392018013877

PETRY, C. Paisagens e paisagismo: do apreciar ao fazer e usufruir. Passo Fundo: UPF, 2014. 125p.

PROCHNOW, T. R. .; SILVEIRA, C. M. V. Educação Ambiental: prática e percepções de estudantes de $8^{\text {a }}$ série do ensino fundamental acerca de problemas ambientais locais. Contexto \& Educação, v. 32, n. 103, p. 87-119, 2017.

RAYS, O. A. Planejamento do ensino: um ato político-pedagógico. Revista Espaço Pedagógico. Passo Fundo: v. 3, n. 1, 1996.

SANTO, I. P. O Livro no Livro Infantil: Mecanismo de Incentivo à Leitura no Universo da Criança. Democratizar, Rio de Janeiro, v. 2, n. 3, 2008.

SEGAWA, H. Ao amor do público: jardins no Brasil. São Paulo: Studio Nobel/FAPESP, 1996. 256p.

SILVA, J. M. M. O desenho na expressão de sentimentos em crianças hospitalizadas. Fractal: Revista de Psicologia, v. 22, n. 2, p. 447-456, 2010.

SILVA, L. A. A Natureza Contraditória do Espaço Geográfico. São Paulo: Contexto, 2. ed. 2001.

SOUZA, L. O.; BERNARDINO, A. D. A contação de histórias como estratégia pedagógica na educação infantil e ensino fundamental. Educere et Educare, v. 6, n. 2, p. 235-249, 2011.

TAVARES, P. O desenho como ferramenta universal. O contributo do processo do desenho na metodologia projectual. Revista de Estudos Politécnicos, v. 7, n. 12, p. 07-24, 2009.

TUAN, Y. F. Topofilia: Um estudo da percepção, atitudes e valores do meio ambiente. Tradução: Lívia de Oliveira. Londrina: Eduel, 2012. 
